\title{
Ultraviolet Radiation Biology
}

National Cancer Institute

\section{Source}

National Cancer Institute. Ultraviolet Radiation Biology. NCI Thesaurus. Code C19100.

The field of science that studies the biological effects of ultraviolet radiation. 